\title{
Extraction Efficiencies of Green Tea Bioactive Metabolites and their Anti-Diabetic Activity
}

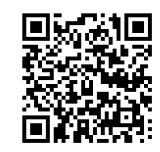

\author{
Protiva Rani Das and Jong Bang Eun* \\ Department of Food Science and Technology, Graduate School of Chonnam National University, South Korea \\ *Corresponding author: Jong Bang Eun, Department of Food Science and Technology, Chonnam National University, 77 Yongbong-ro Buk-gu, \\ Gwangju 61186, South Korea
}

Submission: February 25, 2018; Published: October 05, 2018

\begin{abstract}
Green tea is considered as the most popular beverage in the world due to their higher antioxidant's contents, good taste, aroma, and lately reported health benefits. Green tea bioactive compounds have many beneficial health effects against cancer, cardiovascular disorders, obesity, diabetics and inflammatory disorders etc. Thus, these health functionalities of green tea extract mainly depend on the number of bioactive metabolites are extracted during green tea infusions preparation. Several factors can influence the extraction yields of green tea derived bioactive metabolites including extraction temperature, time, solvents, and solvent to solid ratio etc. However, this review will focus on the extraction efficiencies of green tea metabolites and their effect on type 2 diabetes with possible mechanistic exploration.
\end{abstract}

Keywords: Extraction; Green tea; Bioactive compounds; Anti diabetic activity

\section{Introduction}

From ancient time green tea has been used as traditional medicine due to their various health beneficial effects antioxidant, anticancer, antimutagenic, antidiabetic, antimicrobial, neuroprotective and cardiovascular diseases preventing activities $[1,2]$. These potential health functionalities are mainly associated with green tea derived bioactive compounds such as, various polyphenols, flavonoids, amino acids, caffeine, flavanols like, catechin, epicatechin, epigallocatechin gallate, Gallocatechin gallate, gallocatechol, epicatechin gallate, epigallocatechin, catechin gallate [3] and phenolic acid like gallic acid, protocatechuic acid, vanillic acid, galloylquinic acid, coumaroyl quinin acid, ferulic acid, sialic acid, and galloylated glucose derivatives [2]. Recently, the health benefits in relation to diabetes from natural antioxidant compounds are in focus of scientific investigation due to their less undesirable adverse effects [4]. Diabetic Mellitus (DM), a complex and progressive metabolic disorder, may lead to various health complications and one of the leading cause deaths in the world [5]. Among two types of diabetes, type 2 diabetes mellitus (T2DM), serious chronic diseases accompanied by cellular mediated destruction of pancreatic $\beta$ cell and attendant several health complications such as cardiovascular diseases and oxidative damages etc. [6]. Epidemiologically, it has been suggested that green tea bioactive metabolites were demonstrated to modify glucose metabolism and reduces the risk of diabetes [5,7-10].

Extraction amounts of the bioactive polyphenols during the preparation of green tea extracts can facilitate the nutritional values and provides health benefits. Brewing conditions, including water temperature, solid to solvent ratio, time and extraction techniques, contribute to the amounts of bioactive compounds within the tea infusion [3].

Despite the considerable differences in the bioactive metabolites of green tea extracts obtained by different extraction techniques and conditions, studies comparing the anti-diabetic activities of different green tea extracts are limited. Therefore, this review will focus on extraction efficiencies of green tea metabolites and their anti-diabetic activities.

\section{Extraction efficiencies of green tea bioactive metabolites}

The suitable extraction conditions are influential to increase the extraction yield of green tea polyphenols that will elevate the health functionalities. Many extraction techniques have been used to extract phenolic compounds like hot water extraction, microwave-assisted extraction, supercritical fluid extraction, ultrasonication extraction etc. [3]. Green tea major catechin and phenolic compounds extraction yields are dependent on the extraction parameters, solvent, ratio of solvent to material, extraction temperature and time. In respect to extraction temperature and time, it is advisable to use either a combination of high temperature and short extraction time, or lower temperature and longer extraction time to increase the extraction efficiency and a higher ratio of solvent to material gave better yields [11]. In addition, the application of different exaction techniques could increase the extraction yields of bioactive compounds [3].

\section{Green tea extracts and anti-diabetic activity}

Green tea flavonoids have been used to investigate the hyperglycemic effects using different in-vivo models $[5,7,8,10]$. 
The effects of green tea extracts on hyperglycemic activities are described in Table 1 . The anti-diabetic activity of $70 \%$ green tea extracts (GTE) and black tea extract was conducted in mice model [5]. Authors observed that GTE was more effective in hyperglycemic activity through lowering blood glucose levels and ameliorated glucose intolerance. The possible mechanism for the anti-diabetic activity of GTP was explored by insulin resistance (IR) and $\beta$-cell function (B\%) using homeostatic model assessment (HOMA) to find out the relationship between hepatic glucose and insulin in the basal state that, reflects the balance between hepatic glucose output and insulin secretion. This result indicated that GTE was potential to suppress the IR whereas, in diabetic group was higher. In contrast, $\beta$-cell function was also higher with GTE treatment. This might be due to the presence of $71.5 \%$ catechins in green tea extracts. The effects of polyphenols present in aqueous green tea extract were conducted by in diabetic rat induced by alloxan [7]. The result found that green tea extract at a dose of $100 \mathrm{mg} / \mathrm{kg}$ (b.wt.) was potential to reduce serum glucose level and the daily consumption (15\%) at $50,100 \mathrm{mg} / \mathrm{kg}$ (b.wt.) showed 29 and $44 \%$ reduction. Green tea extracts also increased the liver glycogen, which was decreased due to alloxan treatment and showed antioxidant potentials through increased the superoxide dismutase and glutathione levels.

Hyperglycemic effects of green tea ethanol extract using glucose tolerance methods on rats were studied [8]. From the results, the consumption of $720 \mathrm{mg} / \mathrm{kg}$ (b.wt.) of green tea ethanol extract could reduce the glucose content in the body at 120,180 and 240 minutes after application. In contrast, the application of 180 and $360 \mathrm{mg} / \mathrm{kg}$ (b.wt.) of green tea ethanol extract reduced body glucose content at 180 and 240minutes, respectively.

The effects of green tea water extract $(65 \mathrm{mg} / \mathrm{kg})$ on serum paraoxonase/aryl esterase activities and lipoprotein ionizability in streptozotocin-induced diabetic rats was studied [11]. The result indicated that the green tea ethanol extract was capable to increase the serum total antioxidant ability. Finally, the author group concluded that green tea ethanol extract had antihyperlipidemic and antioxidative effects and slowed the progression of atherogenesis by reducing oxidation of lipoproteins and preserving paraoxonase activity.

Therefore, the anti-diabetic mechanism of natural polyphenols including green tea derived bioactive compounds might be the reduction of bold glucose levels, increase $\beta$-cell function, increase glucose uptake (via increasing GLUT4, p13k), decrease lipid accumulation and glucose production etc. [2] are described in (Figure 1) C/EBP $\alpha$ : CCAAT-enhancer-binding protein $\alpha$; FAS-fatty acid synthase; GLUT4: glucose transporter 4; G6Pase: glucose-6phosphatase; HMG-CoA reductase: 3-hydroxy-3-methylglutaryl coenzyme A reductase; INS: insulin gene; PDX-1: pancreatic and duodenal homeobox 1; PEPCK: phosphoenolpyruvate carboxykinase; P13K: phosphatidylinositol-3-kinase; PPARperoxisomal proliferator-activated receptor).

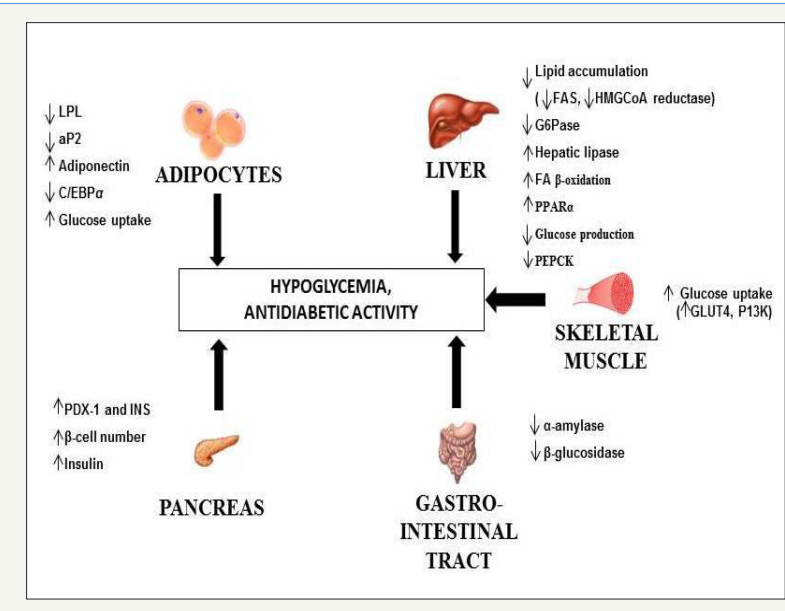

Figure 1: Mechanisms for anti-diabetic effects of natural.

Table 1: Anti-diabetic activities of different green tea extracts.

\begin{tabular}{|c|c|c|c|c|}
\hline Sample & $\begin{array}{l}\text { Types of } \\
\text { Extracts }\end{array}$ & Experiment type & Results & References \\
\hline $\begin{array}{l}\text { Commercial } \\
\text { green tea extract }\end{array}$ & $70 \%$ extract & $\begin{array}{l}\text { In vivo experiment } \\
\text { using female CD-1 mice } \\
\text { model }\end{array}$ & $\begin{array}{l}\text { hypoglycemic effects through reduces the insulin } \\
\text { resistance }\end{array}$ & 5 \\
\hline Green tea & $\begin{array}{l}\text { Aqueous } \\
\text { extract }\end{array}$ & $\begin{array}{l}\text { In vivo experiment us- } \\
\text { ing Wister rat model }\end{array}$ & lipid peroxidation inhibition & 7 \\
\hline Green tea & $\begin{array}{l}\text { Ethanol ex- } \\
\text { tract }\end{array}$ & $\begin{array}{l}\text { In vivo experiment } \\
\text { using rat model }\end{array}$ & reduce glucose content & 8 \\
\hline Green tea & $\begin{array}{l}\text { Aqueous ex- } \\
\text { tract at } 38^{\circ} \mathrm{C} \\
\text { for } 15 \mathrm{~min}\end{array}$ & $\begin{array}{l}\text { In vivo experiment rat } \\
\text { model }\end{array}$ & $\begin{array}{l}\text { antihyperlipidemic and antioxidative effects by reduc- } \\
\text { ing oxidation of lipoproteins and preserving paraoxo- } \\
\text { nase activity. }\end{array}$ & 10 \\
\hline
\end{tabular}




\section{Concluding Remarks and Future Prospective}

The effects of green tea extract regarding anti-diabetes are summarized in Table 1 and their possible mechanistic approaches are described in Figure 1. The anti-diabetic potentials of green tea extracts can be substitute for other commercial anti-diabetic drugs. Green tea intake at different concentration showed significantly decreased in blood glucose level through different mechanism. However, the anti-diabetic activities of green tea extracts are mainly dependent on presence of their bioactive compounds. Therefore, further studies need to demonstrate the effects of different new extraction techniques to increase green tea bioactive metabolites yield and improving anti-diabetic activity.

\section{References}

1. Cao X, Ito Y (2004) Preparation and purification of epigallocatechin by high speed countercurrent chromatography (HSCCC). Journal of Lipid chromatography \& Related Technologies 27(1): 145-152.

2. Das PR, Eun JB (2016) Phenolic acids: properties, food Sources and health effects. In: A Flores (Ed.), Phenolic acids in tea and coffee and their health benefits. Nova Science Publishers, New York, USA, pp. 104129.

3. Parsija D, Ananda RC (2015) Techniques for extraction of green tea polyphenols: a review. Food Bioprocess Technology 8(5): 935-950.

4. Ranilla LG, Kwon YI, Apostolidis E, Shetty K (2010) Phenolic compounds, antioxidant activity and in vitro inhibitory potential against key enzymes relevant for hyperglycemia and hypertension of commonly used medicinal plants, herbs and species in Latin America. Bioresour Technol 101(12): 4676-4689.

5. Tang W, Li S, Liu Y, Huang MT, Ho CT (2013) Anti-diabetic activity of chemically profiled green tea and black tea extracts in type 2 diabetes mice model via different mechanisms. Journal of Functional Foods 5(4): 1784-1793.

6. Kim YM, Jeong YK, Wang MH, Lee, WY, Rhee HI (2005) Inhibitory effect of pine extract on $\alpha$-glucosidase activity and postprandial hyperglycemia. Nutrition 21(6): 756-761.

7. Sabu MC, Smitha K, Ramadasan K (2002) Anti diabetic activity of green tea polyphenols and their role in reducing oxidative stress in experimental diabetes. Journal of Ethnopharmacology 83(1-2): 109116.

8. Rohdiana D, Firmansyah A, Setiawati A, Yunita N (2012) Antidiabetic activity of green tea ethanol extract on white mouse. Jurnal Penelitian Teh dan Kina 15(1): 32-39.

9. Tsuneki H, Ishizuka M, Terasawa M, Wu JB, Sasaoka T, et al. (2004) Effect of green tea on blood glucose levels and serum proteomic patterns in diabetic $(\mathrm{db} / \mathrm{db})$ mice and on glucose metabolism in healthy humans. BMC Pharmacol 26(4): 1-8.

10. Tas S, Sarandol E, Ziyanok S, Aslan K, Dirican M (2005) Effects of green tea on serum paraoxonase/arylesterase activities in streptozotocininduced diabetic rats. Nutrition Research 25(2): 1061-1074.

11. Perva UA, Skerget M, Knez Z, Weinreich B, Otto F, et al. (2006) Extraction of active ingredients from green tea (Camellia sinensis): Extraction efficiency of major catechins and caffeine. Food Chemistry 96(4): 597605.

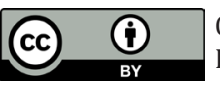

Creative Commons Attribution 4.0

International License

For possible submissions Click Here

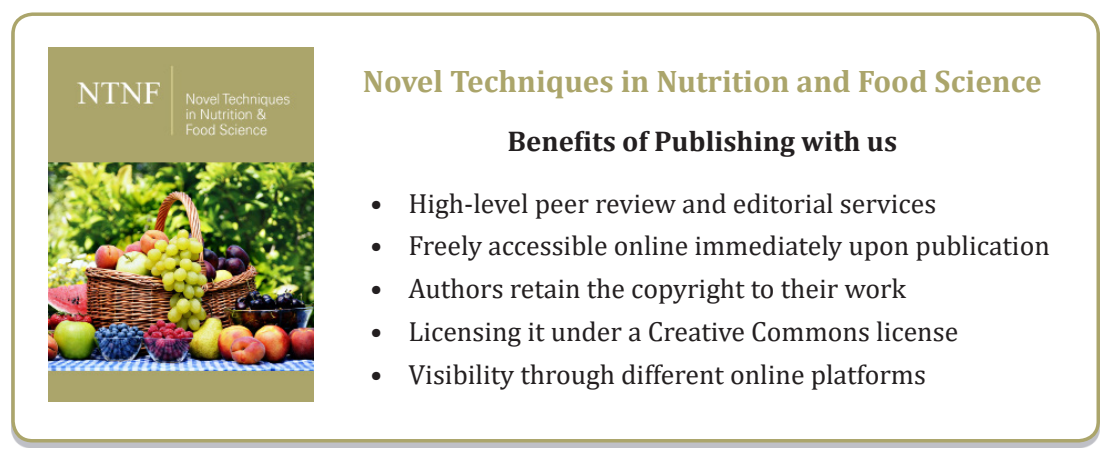

